\title{
Participación política de las FARC-EP y apertura democrática para la construcción de la paz en Colombia: una aproximación esquemática
}

\author{
Political participation of the FARC-EP and democratic opening for the \\ construction of peace in Colombia: a schematic approach.
}

\author{
Janiel David Melamed Visbal ${ }^{*}$
}

\begin{abstract}
Resumen: Colombia presenta un contexto de violencia activo, que se ha prolongado durante muchas décadas y que a lo largo de este tiempo ha sido sometido a diferentes mutaciones. Este conflicto armado tiene múltiples actores y causas, pero a lo largo de los años ha mantenido una constante: El uso de la violencia como herramienta para la consecución de objetivos políticos. Esta circunstancia ha consolidado un escenario de exclusión política que ha prolongado la confrontación. Por ello, resulta pertinente comprender como en medio del proceso de paz celebrado entre el Gobierno nacional y las FARC-EP se ha acordado la consolidación de espacio de inclusión política de las FARC-EP, para que puedan desarrollar su proyecto político sin armas o violencia. En este sentido, vale la pena analizar ¿En qué consiste este escenario de apertura democrática?
\end{abstract}

Palabras clave: Colombia, Paz, FARC-EP, Participación política, Democracia.

\begin{abstract}
Colombia presents a context of active violence, which has lasted for many decades and has undergone different mutations over the years. This armed conflict has multiple actors and causes, but over the years has maintained a constant characteristic: The use of violence as a tool for achieving political objectives. This circumstance has consolidated a scenario of political exclusion that has prolonged the confrontation. Therefore, is important to understand how in the midst of the peace process between the national government and the FARC-EP, it has been agreed to consolidate the political inclusion of FARC-EP, so that they can develop their political project without weapons or violence. In this sense, it is worth analyzing what are the main attributes and components of this scenario of democratic openness?
\end{abstract}

Key words: Colombia, Peace, FARC-EP, Political participation, Democracy

Recibido: 23 junio 2017

Aceptado: 20 agosto 2017

${ }^{*}$ Ph.D en Seguridad Internacional. Actualmente es docente investigador del Departamento de Ciencia Política y Relaciones Internacionales de la Universidad del Norte en Barranquilla-Colombia. jmelamed@uninorte.edu.co 


\section{Introducción}

Una de las causas principales que pueden atribuirse el surgimiento y profundización del conflicto armado en Colombia se fundamenta en las profundas falencias del sistema político nacional y profundas dificultades a nivel social. En este sentido, el Centro Nacional de Memoria Histórica (2014, p. 31) relaciona el origen de las FARC-EP con tres fenómenos sociopolíticos importantes como son las luchas agrarias del siglo XX, la actividad política del Partido Comunista y la creación de las autodefensas campesinas a causa de la violencia bipartidista.

Es importante resaltar como las FARC-EP nacieron originalmente como una estructura eminentemente campesina del Partido Comunista Colombiano en zonas rurales bajo el intento de organizar al naciente movimiento obrero, campesino y sindical en el país a comienzo del siglo XX, proclamando la reivindicación de los intereses de los menos favorecidos frente a la desidia y abandono estatal (Trejos \& González, 2013, p. 65). Esta organización seria declarada ilegal en 1948, sus sedes fueron ocupadas por la policía nacional, se emitieron órdenes de captura en contra de su dirigencia política y se prohibió la circulación de sus medios de prensa, por lo que sus miembros y simpatizantes evidenciaron un proceso de persecución que los llevaría a dispersarse principalmente en el sector rural (Pizarro, 2011, p. 39).

El justificante que enarboló esta organización se mantendría a lo largo de su historia y encontraría fundamento en la histórica implementación de la fuerza represiva del Estado en contra de militantes liberales y comunistas, en un momento donde la coyuntura política internacional estaba ya condicionada por la guerra fría y en la consagración de bipartidismo en cabeza de liberales y conservadores (Trejos, 2015, p. 25). Estos partidos políticos tradicionales durante la mayor parte de la historia política del país se consolidaron como actores hegemónicos y excluyentes del poder, negando cualquier posibilidad de relevancia política a fuerzas opositoras o contradictorias, impidiendo con ello la adecuada consolidación de un desarrollo democrático integral a nivel nacional. Quizás una de las manifestaciones más notorias y relevantes en este marco de exclusión política y bipartidismo hegemónico se encuentran en la creación del Frente Nacional ${ }^{1}$. Al respecto

1 El acuerdo del Frente Nacional determinó la manera como se repartiría el poder político en Colombia durante los siguientes 4 periodos presidenciales (1958-1974). Según Gutiérrez, Acevedo \& Viatela (2007, p. 15) este acuerdo se fundamentó en torno a 4 ejes fundamentales, el primero respecto a la alternancia del mandato presidencial entre el Partido Liberal y el Partido Conservador, de tal manera que cada uno de ellos tuviera dos periodos presidenciales de manera intercalada. El segundo eje estableció la suspensión de cualquier tipo de investigación o sanción impuesta como consecuencia del espiral de violencia bipartidista en las que estuvieron involucrados en el pasado. El tercer eje estableció un reparto igualitario de la representación política de cada uno de estos partidos en el Congreso de la República y estableció un sistema de mayorías cualificadas que requería de las $2 / 3$ partes de los votos en el Congreso para la aprobación de cualquier ley. Esta circunstancia aseguraría que los congresistas oficialistas contaran con un acceso garantizado a los recursos del Estado, obteniendo por ello una reproducción electoral individual (Duque, 
Mesa (2009, p. 173) destaca el carácter antidemocrático del acuerdo político entre liberales y conservadores y que originaría el Frente Nacional, cuando señala:

(...) La misma naturaleza del pacto que, como se vio, era excluyente, generaría los más graves problemas sociales en los próximos años. La incorporación limitada de los sectores populares y la poca presencia organizada y autónoma de estos demostrarían a la larga lo limitada que era la participación política y, por ende, lo restrictiva que era la democracia. Se generó una tensión en las relaciones entre la élite y las masas en un predominio estructurado de la elite.

Es en este contexto en que la violencia se ha consolidado como instrumento histórico para la concesión de objetivos políticos en Colombia. De ahí se desprende la importancia de como al interior del proceso de negociación adelantado entre el Gobierno nacional y las FARC-EP en La Habana, quizás uno de los puntos que mayor atención y expectativa generó se refería a la adopción de medidas de apertura democrática que permitieran finalmente, dentro del marco de la legalidad, la participación política de las FARC-EP en el escenario democrático nacional.

Este punto constituye, al igual que las demás partes que integran el acuerdo final para la terminación del conflicto y la construcción de una paz estable y duradera, una base fundamental en el anhelado proceso de transición colombiano. Merece la pena destacar que este punto en particular no tiene como finalidad especifica buscar que las FARC-EP alteren drásticamente sus postulados políticos o ideológicos o que declinen su tradicional objetivo de la conquista del poder político en el país. El propósito fundamental de este punto en particular se centra en la posibilidad que las FARC-EP renuncien a la violencia como herramienta sine qua non para la consecución de sus objetivos políticos y que se limiten a las alternativas e instrumentos contemplados en las reglas de juego democrático sin ser sometidos a un proceso de exterminio sistemático.

Esta circunstancia debe concretarse como parte esencial del proceso de desmovilización, desarme y reintegración a la sociedad. Con el propósito de presentar una mayor ilustración respecto al acuerdo de participación política y apertura democrática en Colombia, se presentan a continuación unos esquemas que resumen y organiza su contenido. Con ello se espera favorecer el conocimiento y la comprensión eficaz de estos principios y mecanismos fundamentales para la construcción de una paz estable y duradera en Colombia.

2005, p. 32). Finalmente se estableció una distribución equitativa de la mayor parte de puestos de alto nivel al interior del Gobierno. 


\section{Contenido del Acuerdo final respecto a la participación política}
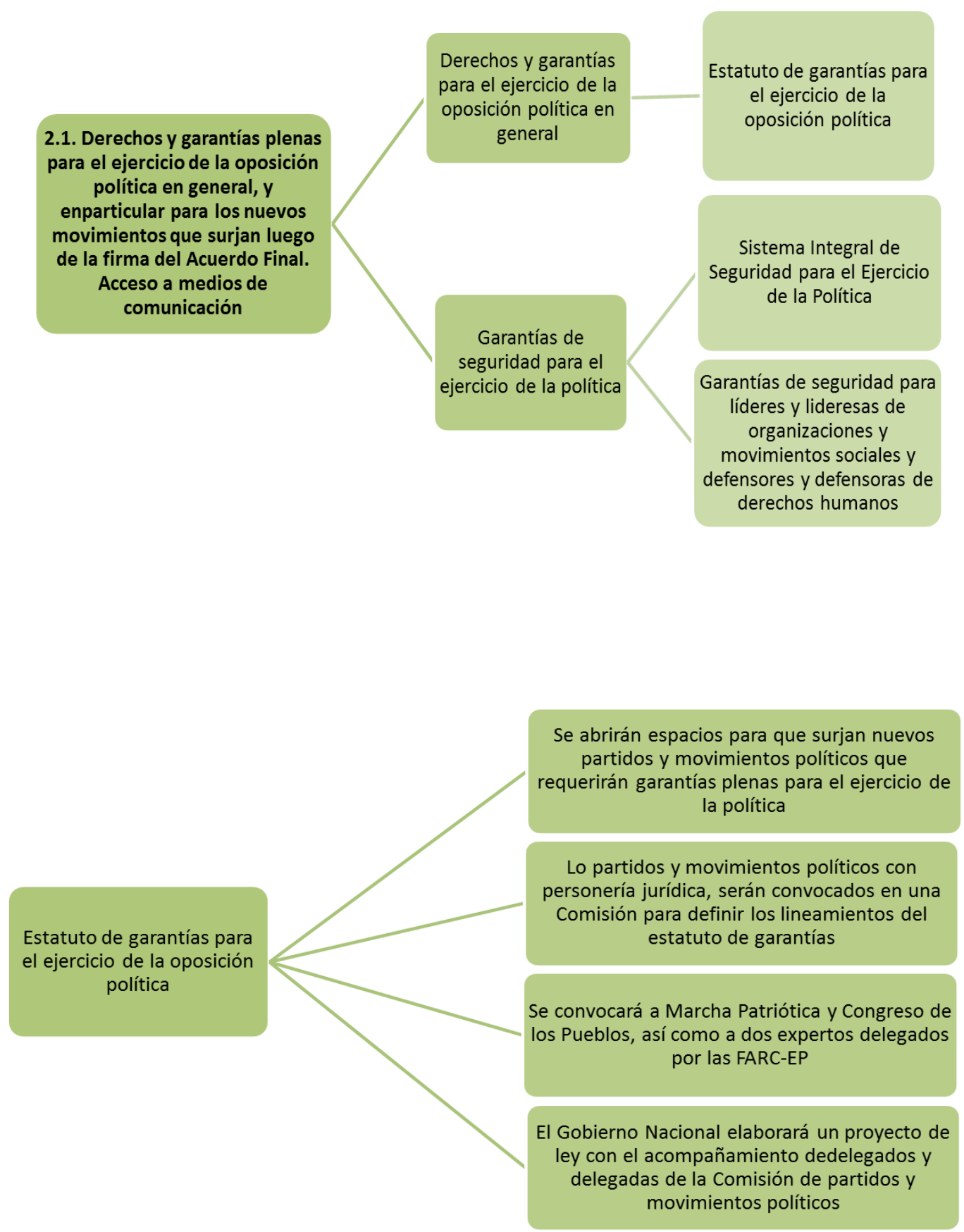


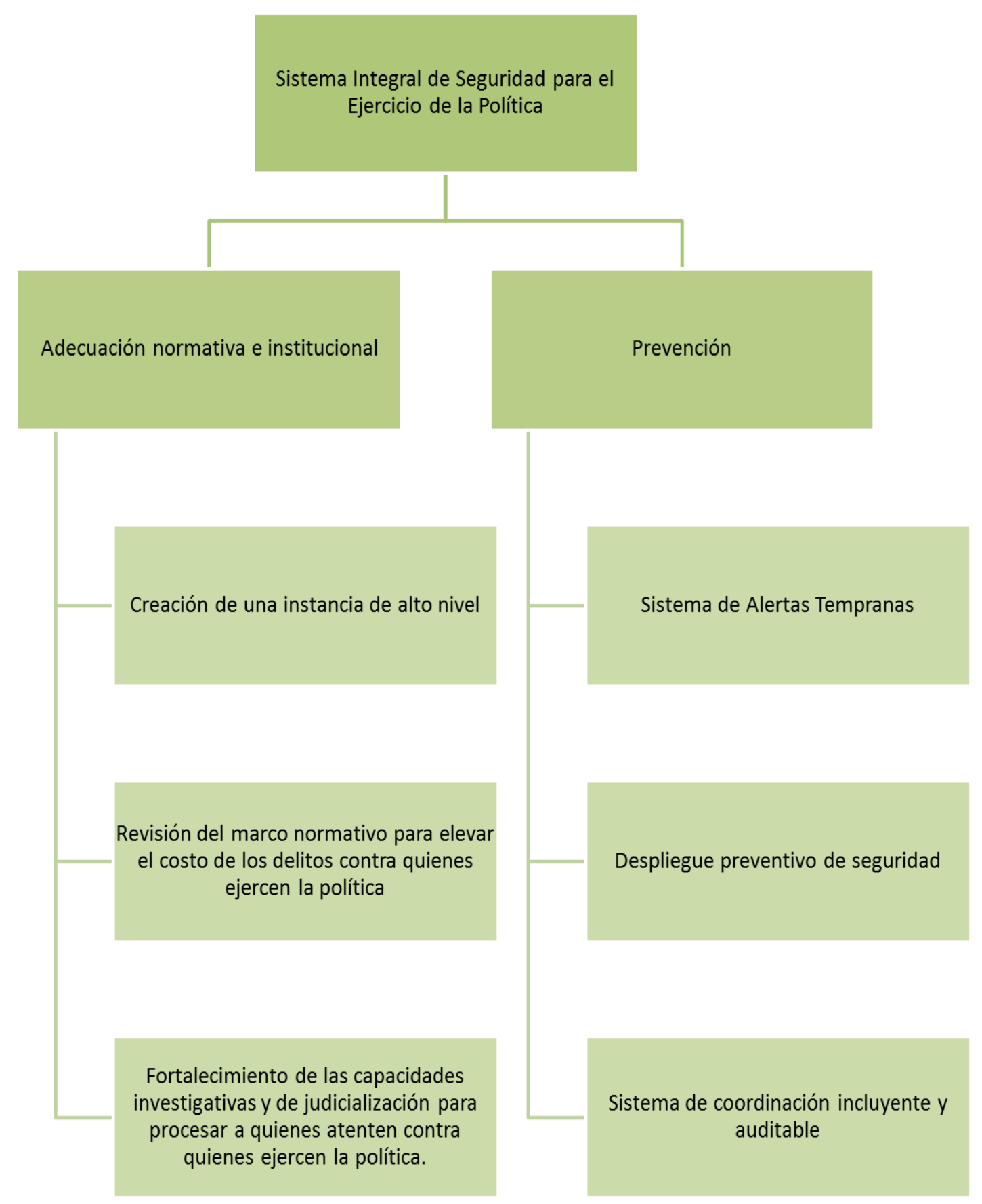




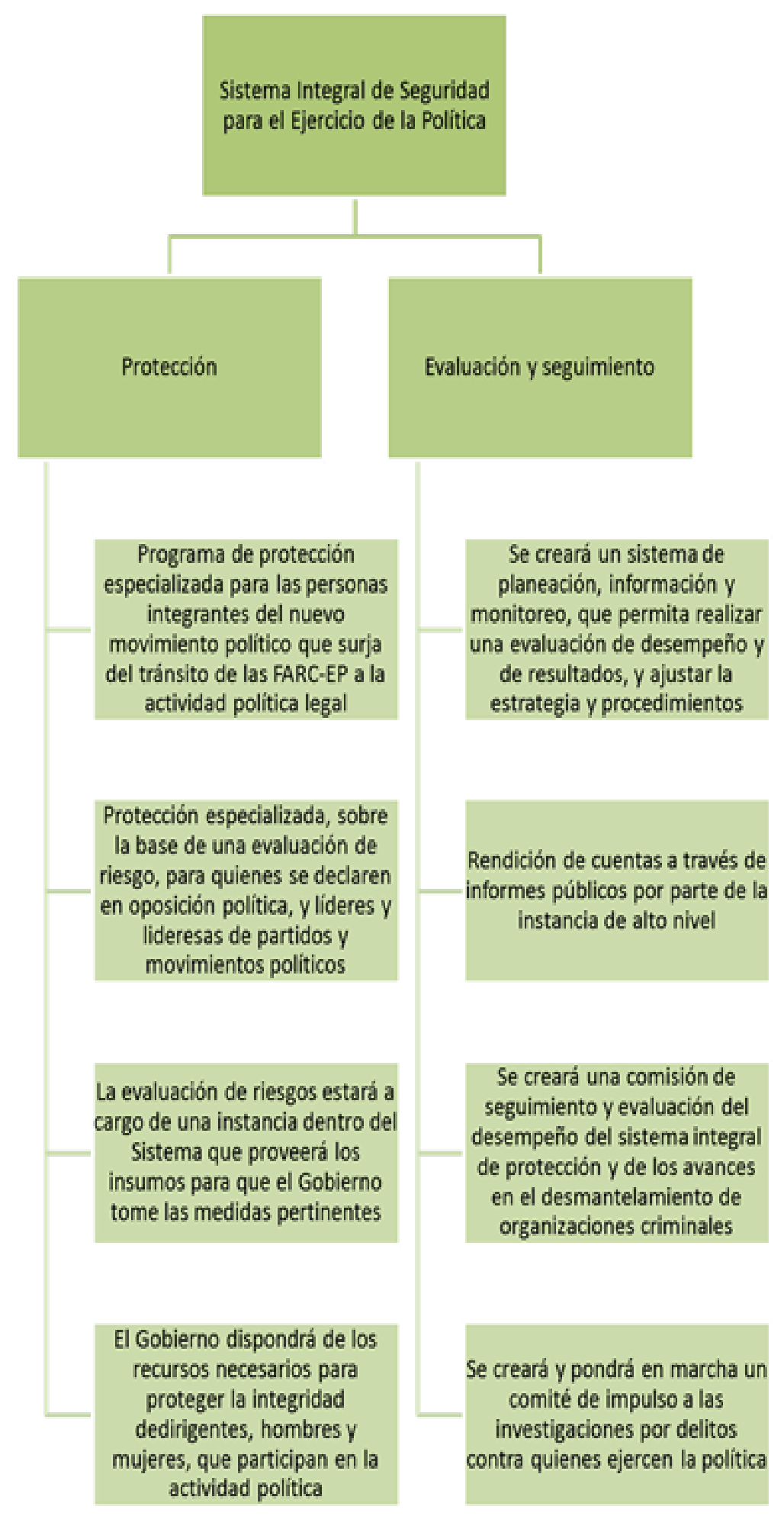




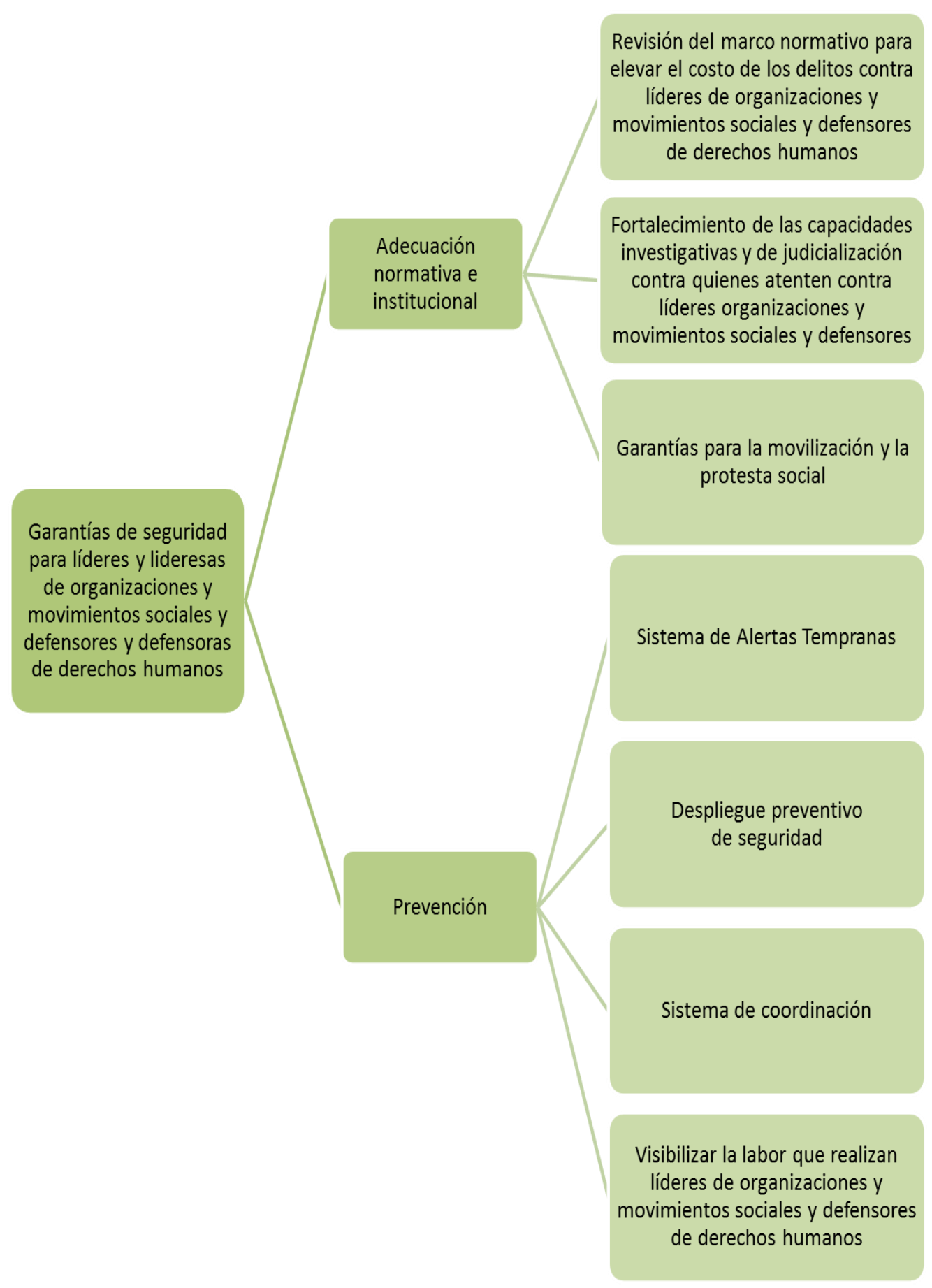




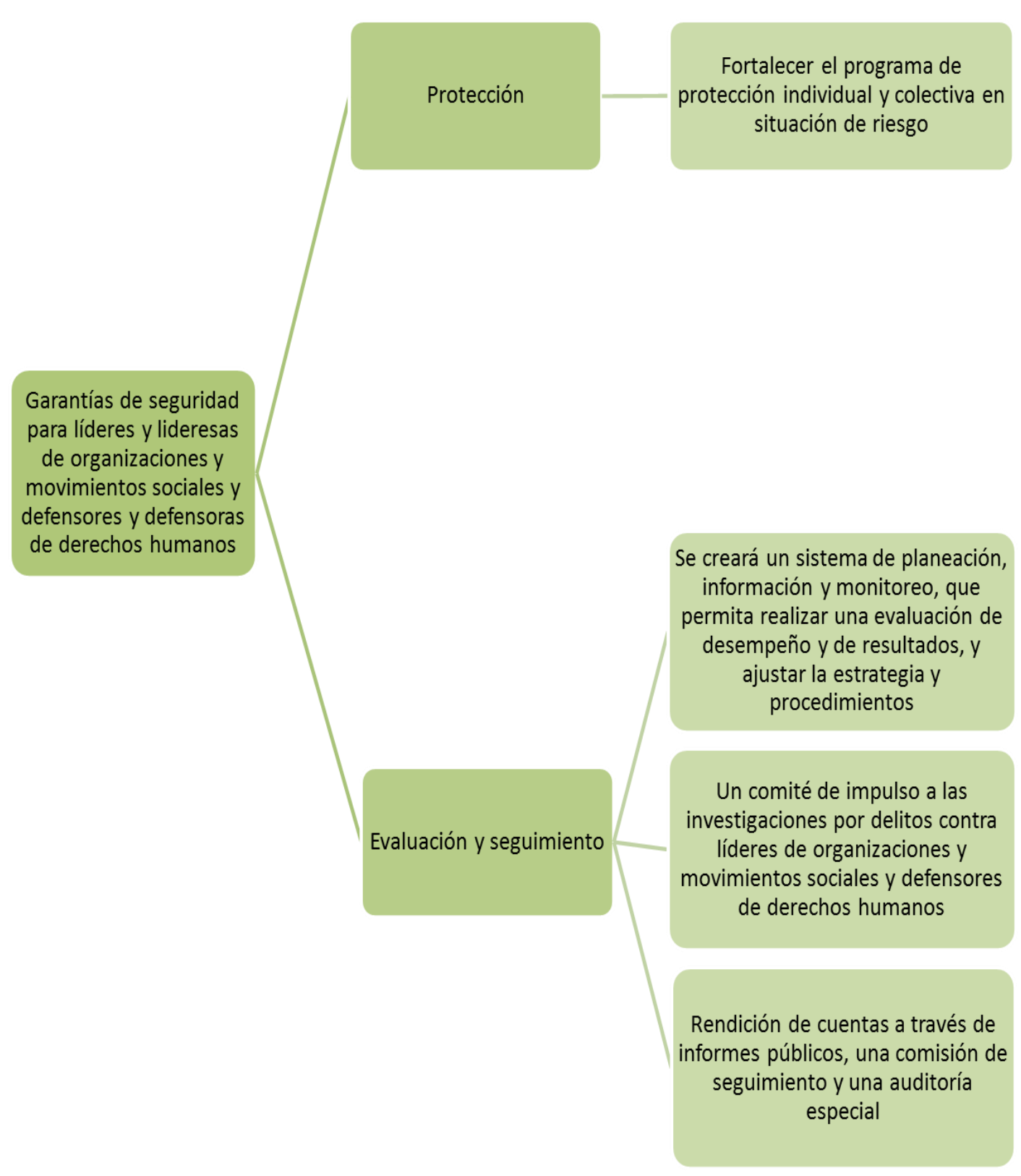




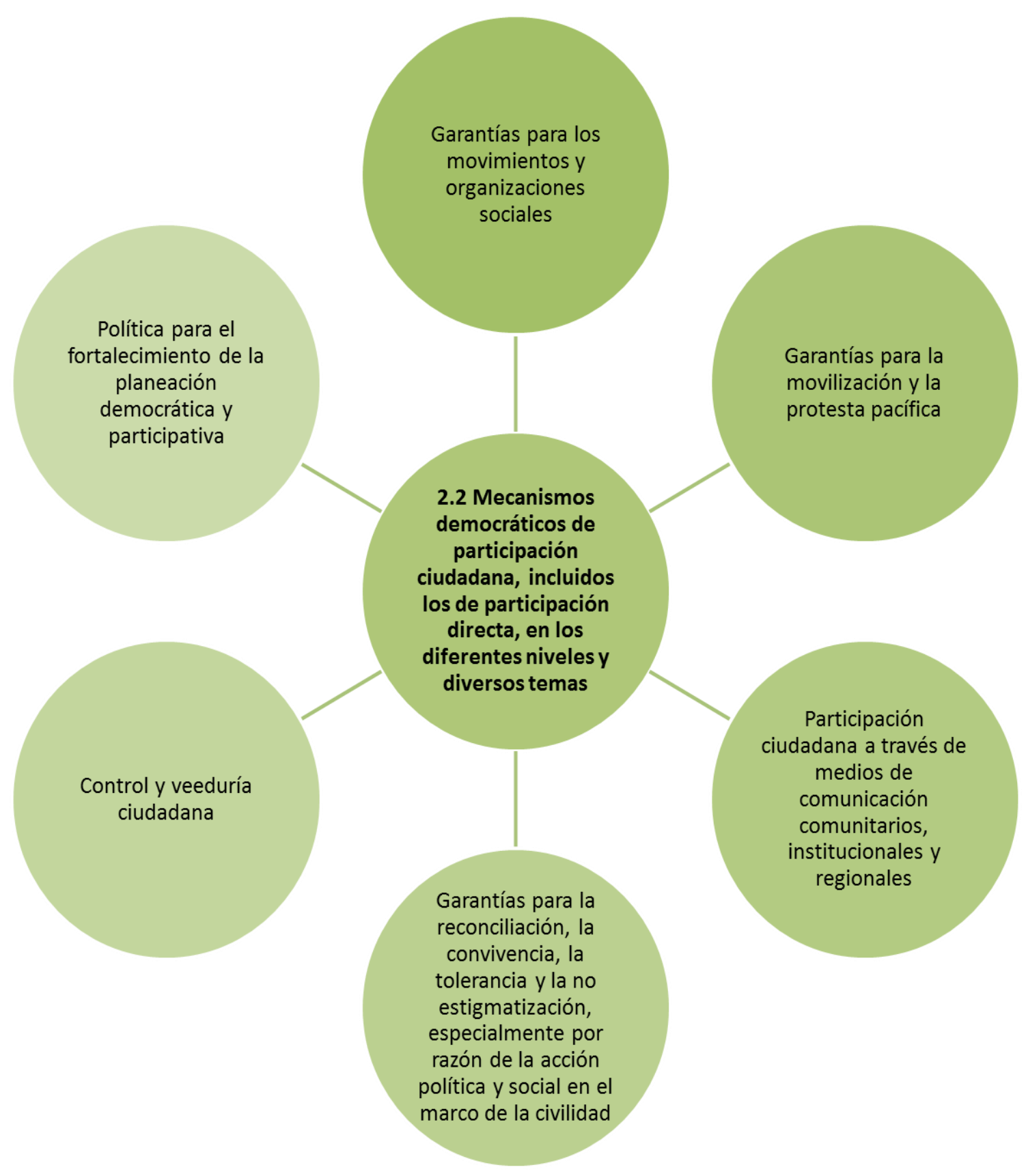


Garantías para los movimientos y organizaciones sociales

Se adoptarán medidas para garantizar el reconocimiento, fortalecimiento y empoderamiento de todos los movimientos y organizaciones sociales, de acuerdo con sus repertorios y sus plataformas de acción social

- Garantizar el derecho al acceso oportuno y libre a la información oficial en el marco de la Constitución y la ley

- Reglamentación del derecho de réplica y rectificación, en cabeza de las organizaciones y movimientos sociales más representativos

- Realizar conjuntamente con las organizaciones y movimientos sociales una caracterización y registro de organizaciones sociales, formales y no formales, que se actualice periódicamente

- Apoyar, mediante asistencia legal y técnica, la creación y el fortalecimiento de las organizaciones y movimientos sociales

- Agilizar la sistematización e intercambio de experiencias exitosas de fortalecimiento de los mismos, y formarlos y capacitarlos para el desarrollo de sus objetivos misionales

- Fortalecer los mecanismos de financiación de iniciativas y proyectos propios de las organizaciones sociales

- Promover la creación de redes de organizaciones y movimientos sociales, especialmente delos que han estado en condiciones de exclusión política

- Acceso a mecanismos de difusión para hacer visible la labor y la opinión de lasorganizaciones, y movimientos sociales

- Se ampliará y garantizará la representatividad con participación equitativa entre hombres y mujeres de las organizaciones y los movimientos sociales

- Diseñar metodologías que contribuyan a la efectividad e incidencia de las instancias de participación e interlocución

- Poner en marcha instancias de seguimiento y verificación del cumplimiento en cuanto al establecimiento, funcionamiento y eficacia de los espacios de participación ciudadana

- Crear una herramienta que permita valorar, hacer visible e incentivar la gestión de las autoridades públicas

- Se garantizará el intercambio de experiencias exitosas de participación ciudadana entre las organizaciones sociales y las autoridades locales y regionales

- Promover la construcción de agendas de trabajo locales, municipales, departamentales y nacionales que permitan la atención temprana de las peticiones y propuestas de los sectores

- Las autoridades locales deberán atender de manera oportuna las peticiones y propuestas, y canalizarlas según su competencia 


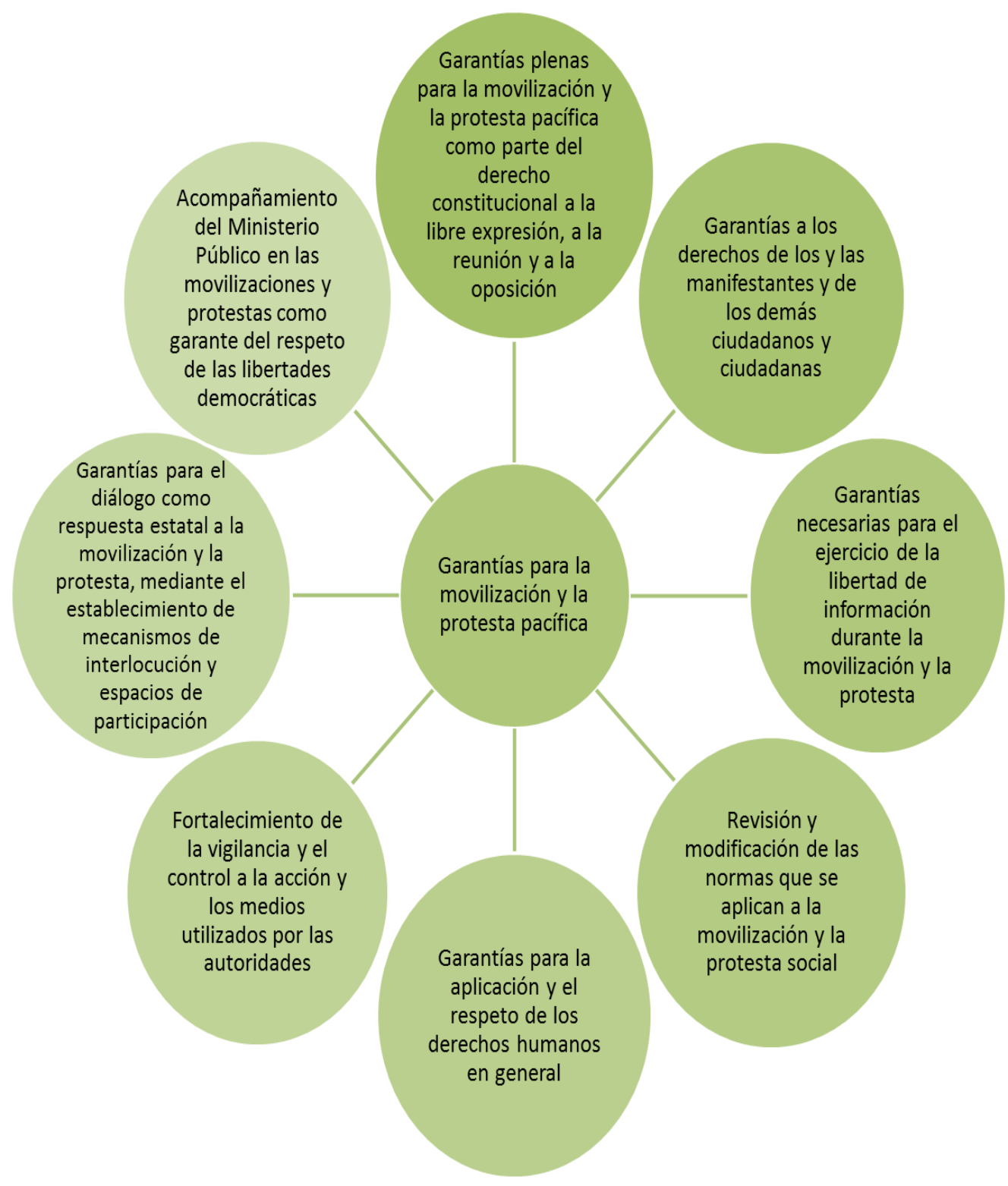


Participación ciudadana a

través de medios de comunicación comunitarios, institucionales y regionales
Abrir nuevas convocatorias para la adjudicación de radio - comunitaria con sujeción a los criterios objetivos establecidos en la ley

Abrir espacios en las emisoras

$y$ canales institucionales y regionales destinados a la divulgación del trabajo de las organizaciones y movimientos sociales

El Gobierno Nacional se compromete a:
Promover la capacitación técnica y formación de los trabajadores de los medios comunitarios, de comunicadores comunitarios y de operadores de medios de comunicación

Financiar la producción y divulgación de contenidos orientados a fomentar una cultura de paz con justicia social y reconciliación 
Garantías para la reconciliación, la convivencia, la tolerancia y la no estigmatización, especialmente por razón de la acción política y social en el marco de la civilidad

El Gobierno creará un Consejo Nacional para la Reconciliación y la Convivencia. Estará integrado por representantes del Gobierno, el Ministerio Público, quienes designen los partidos y movimientos políticos. Sus acciones incluyen:

- Diseñar y ejecutar un programa de reconciliación, convivencia y prevención de laestigmatización, con la participación de las entidades territoriales.

- Promoción del respeto por la diferencia, la crítica y la oposición política

- Promoción del respeto por la labor que realizan en pro de la construcción de la paz y la reconciliación,

- Promoción del respeto por la labor que realizan las organizaciones sociales y de derechos humanos,

- Promoción de la no estigmatización a grupos en condiciones de vulnerabilidad o discriminados

- Capacitar a funcionarios públicos y a líderes de las organizaciones y movimientos sociales para garantizar la no estigmatización

- Capacitar a organizaciones, movimientos sociales y funcionarios en cargos de dirección, en el tratamiento y resolución de conflictos

- Pedagogía y didáctica del Acuerdo Final: impulso de programas de formación y comunicación para la apropiación del Acuerdo

- Diseño y ejecución de campañas de divulgación masiva de una cultura de paz, reconciliación, pluralismo y debate libre de ideas

- Promover la reconciliación, la convivencia y la tolerancia, especialmente en las poblaciones más afectadas por el conflicto

- Capacitar a organizaciones y movimientos sociales, y funcionariospúblicos en cargos de dirección en

el tratamiento y resolución de conflictos.

- Creación de una cátedra de cultura política para la reconciliación y la paz 

Control y veeduría ciudadana control por parte de ciudadanos y la democratización y mayor transparencia de la administración pública, el Gobierno Nacional:

Establecerá un plan de apoyo a la creación y promoción de veedurías ciudadanas y observatorios de transparencia

Creará mecanismos de información de fácil acceso, con -el fin de garantizar la publicidad y transparencia en la implementación

Vinculará a las universidades públicas a campañas masivas para la promoción de la participación ciudadana y del control por parte de ciudadanos

Creará un mecanismo especial para la atención, trámite y seguimiento de denuncias y alertas de ciudadanos por

Con el propósito de promover y fortalecer el posibles hechos de corrupción

Promoverá una masiva campaña institucional de divulgación de - los derechos de ciudadanos y de las obligaciones y deberes de las autoridades

La campaña contemplará la difusión de todos los mecanismos de participación y control por parte de ciudadanos

Fortalecerá los mecanismos de rendición de cuentas de todas las servidoras y servidores públicos de elección popular

Garantizará el apoyo al plan nacional de formación de veedores que promocionen las comunidades.

Contarán con la participación efectiva de las mujeres 

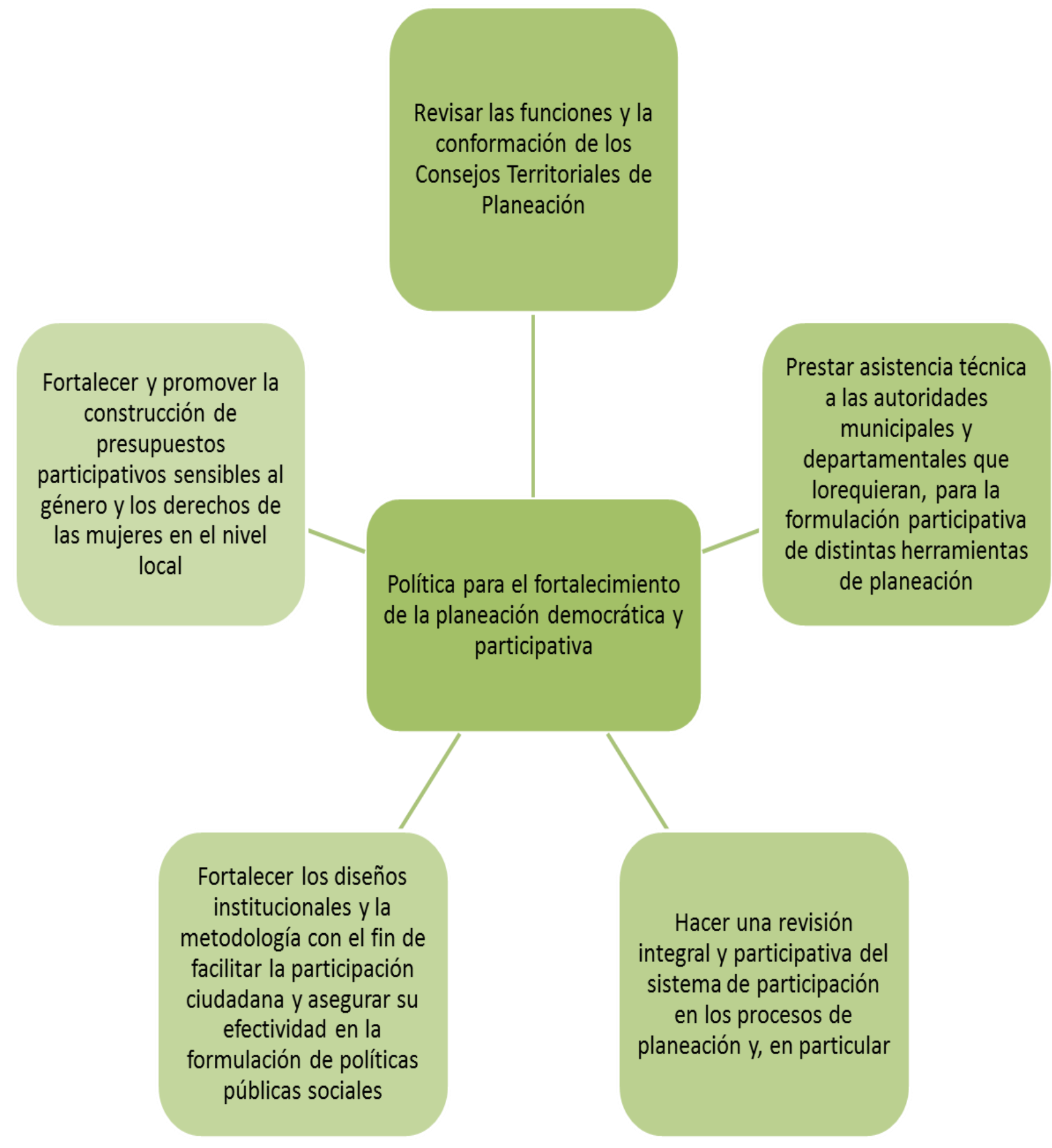

\section{participativa}




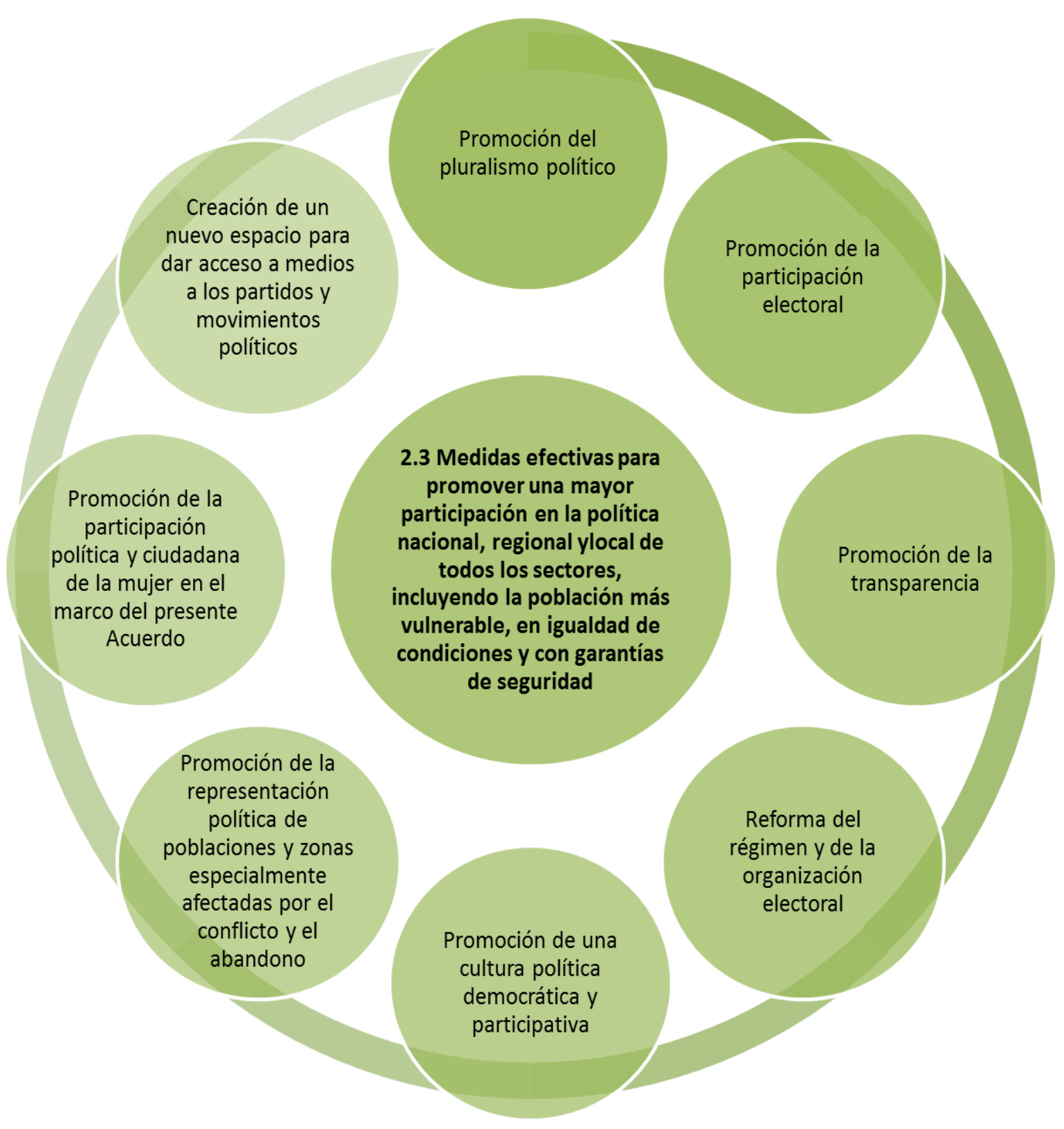




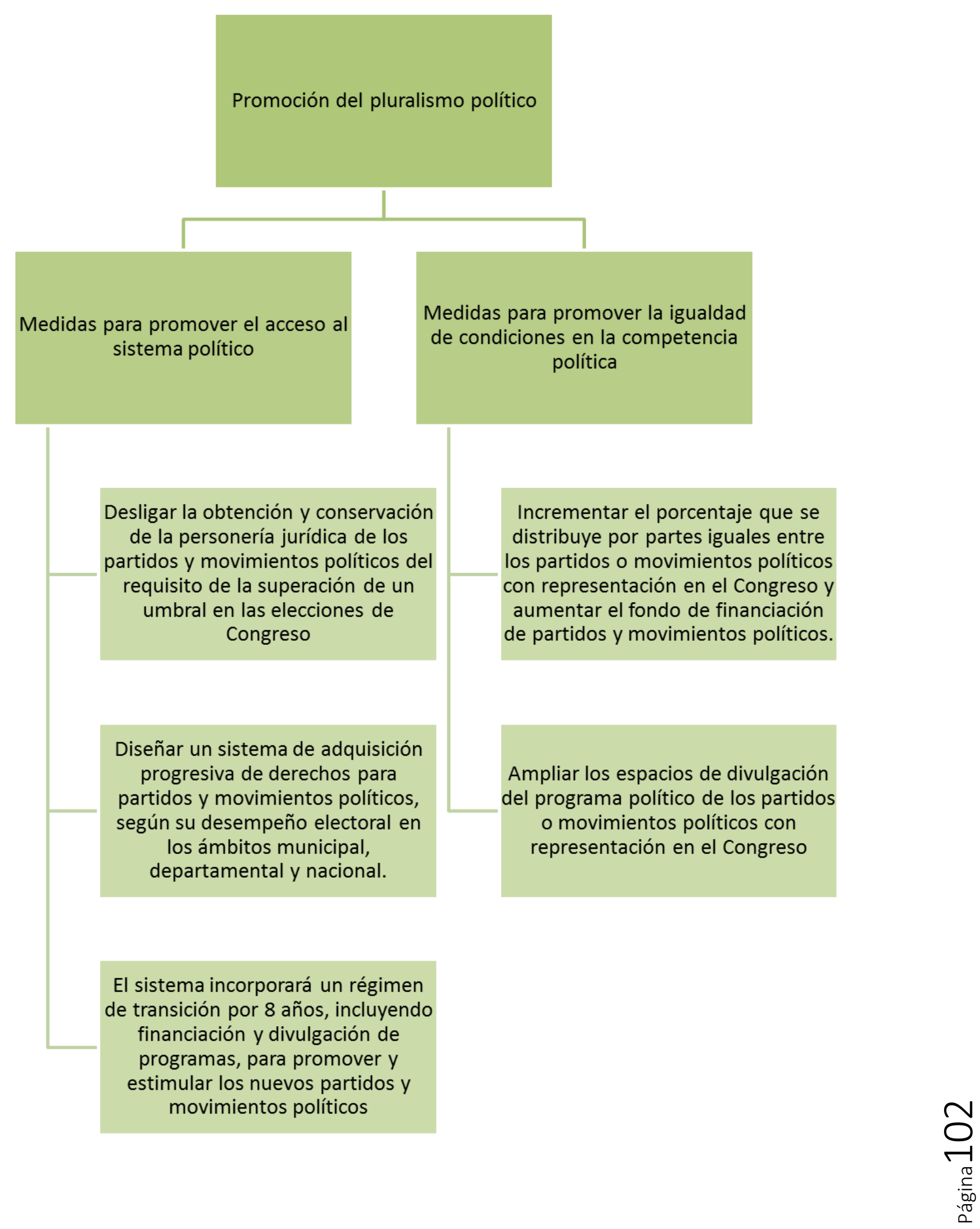




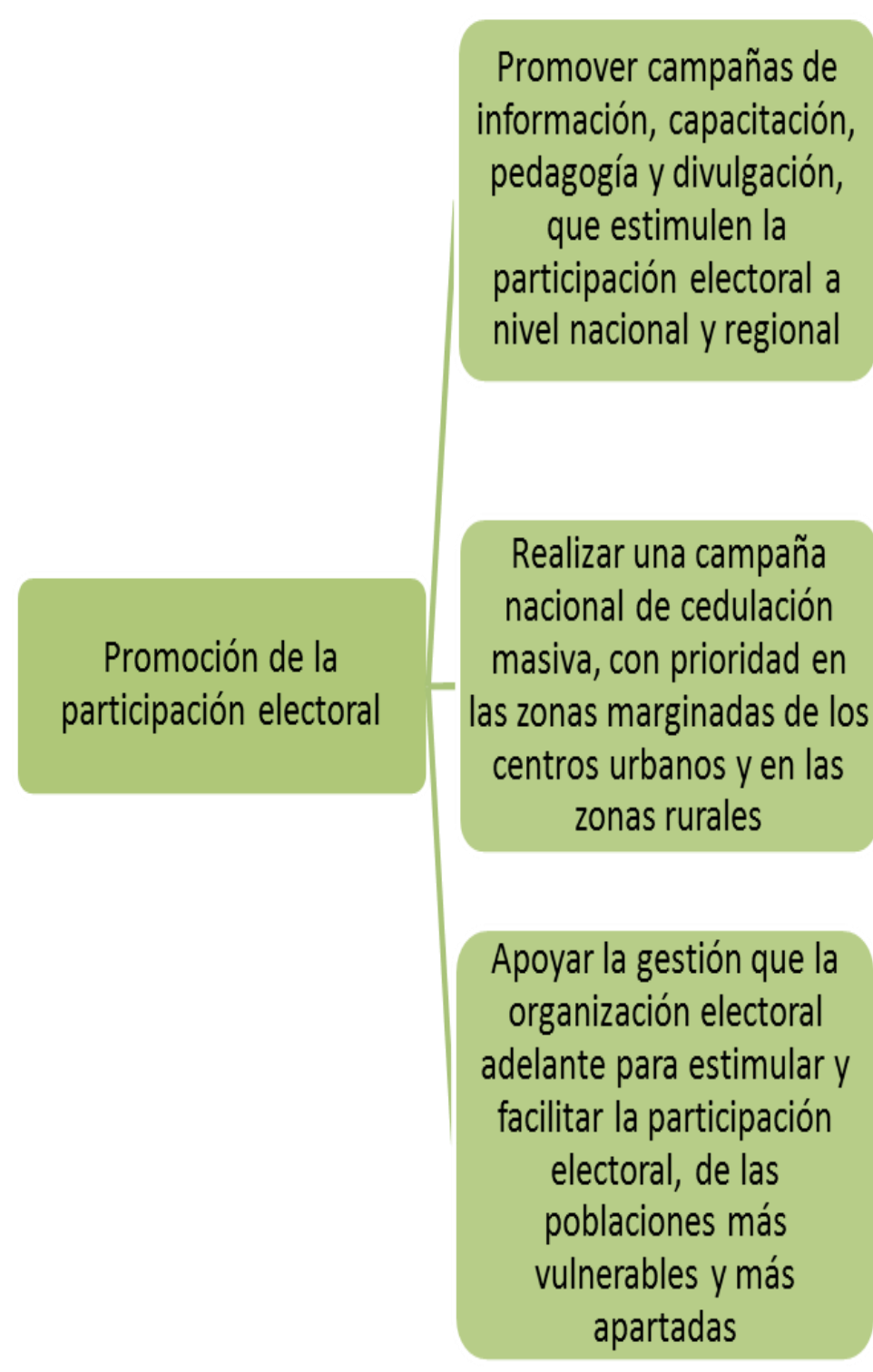

Promover un ejercicio participativo de diagnóstico con enfoque de género, de los obstáculos que enfrentan estas poblaciones en el ejercicio del derecho al voto, y adoptar las medidas correspondientes
Adoptar mecanismos para facilitar el acceso a los puestos de votación de las comunidades que habitan en zonas alejadas y dispersas 


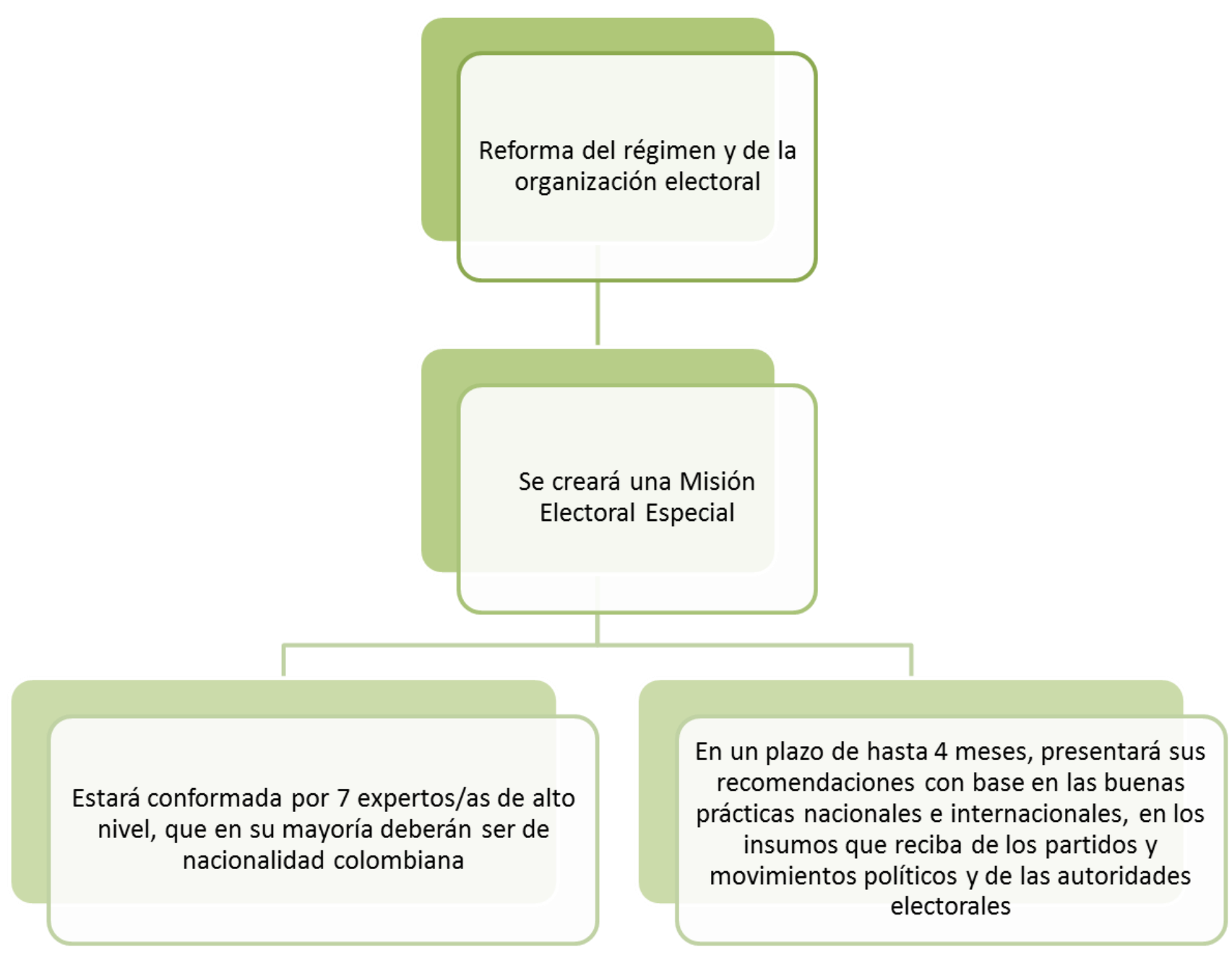

Creación de un nuevo espacio para dar acceso a medios a los partidos y movimientos políticos
El Gobierno se compromete a habilitar un canal institucional de televisión cerrada orientado a lospartidos y movimientos políticos con personería jurídica
Se establecerá una comisión con representantes de los partidos y movimientos políticos y organizaciones y movimientos sociales más representativos para asesorar en la programación del canal 


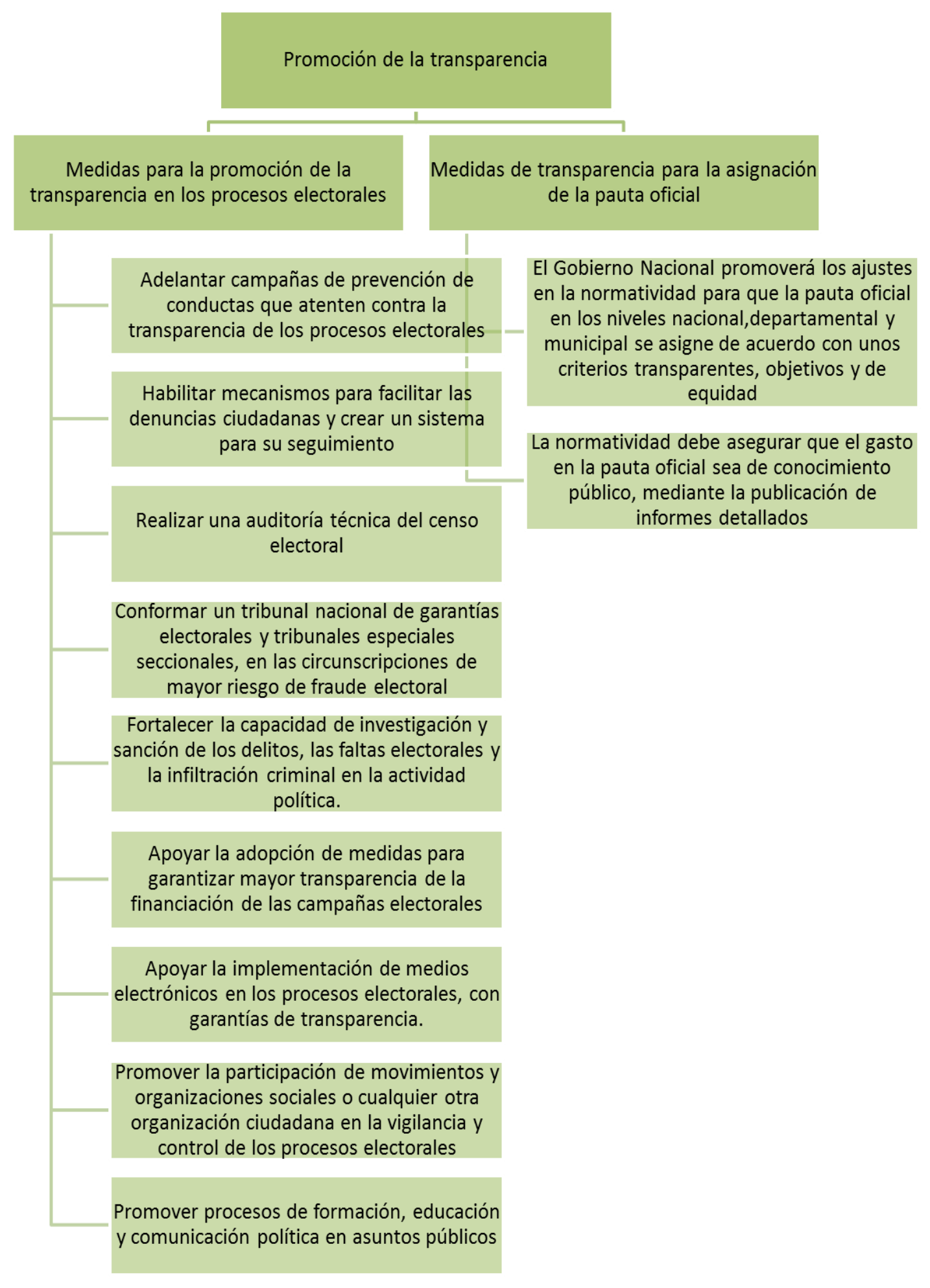




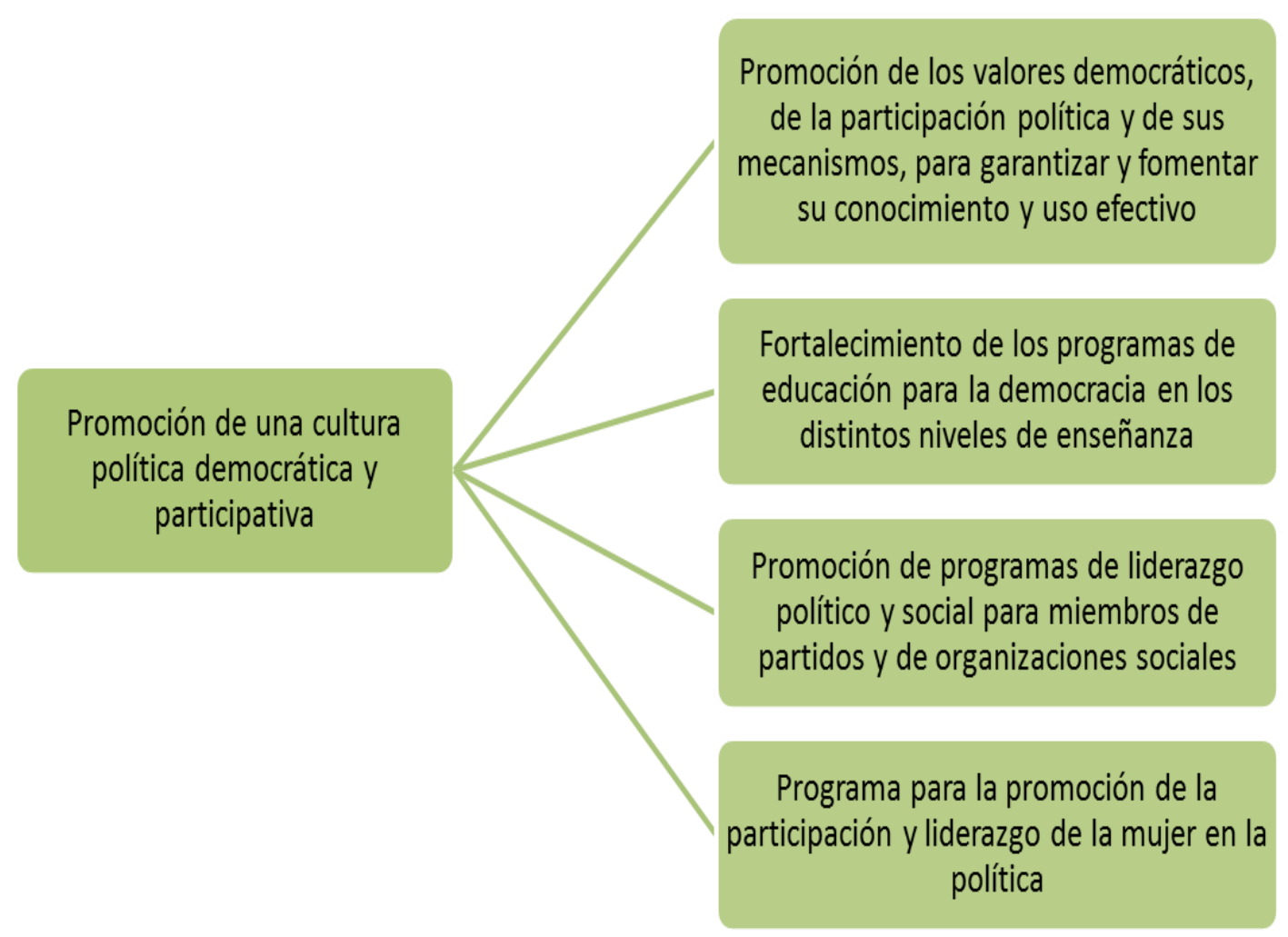

Promoción de la representación política de poblaciones y zonas especialmente afectadas por el conflicto y el abandono
Crear un total de 16 Circunscripciones Transitorias Especiales de Paz para la elección de 16 Representantes a la Cámara de Representantes, de manera temporal y por 2 períodos electorales 


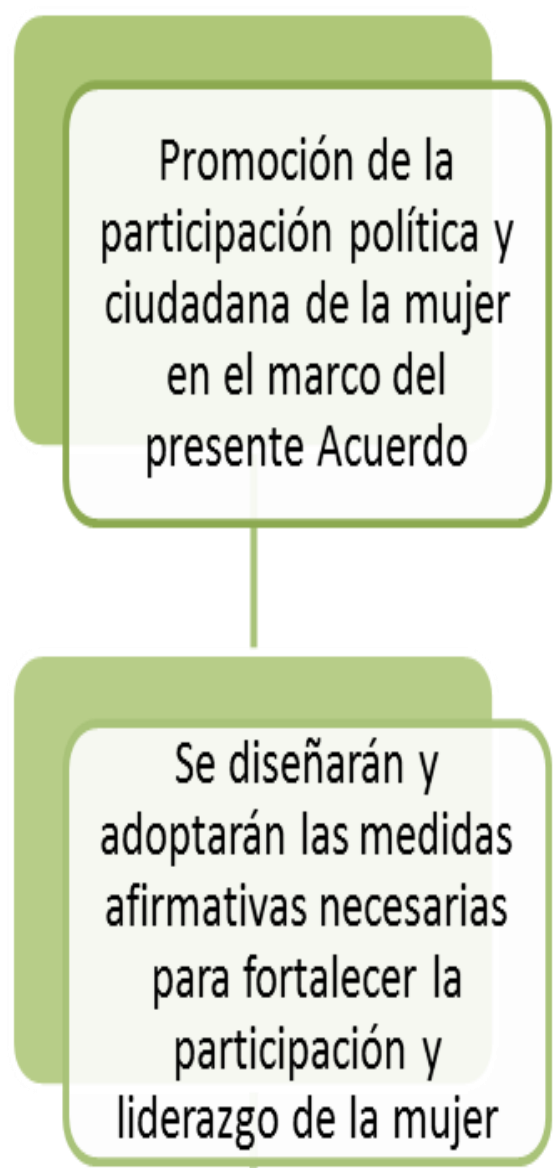

Se requiere propender por la participación equilibrada y el protagonismo de las mujeres al interior de organizaciones y movimientos sociales y partidos políticos
Se pondrán en marcha programas de formación sobre sus derechos políticos y formas de participación política y ciudadana 


\section{CONCLUSIÓN.}

Si bien el origen formal de las FARC-EP data desde la década del sesenta, lo cierto es que la confrontación armada que esta organización guerrillera realiza en contra del Estado colombiano encuentra su razón de ser en otro conflicto anterior, el conflicto político que caracterizó al bipartidismo político tradicional en Colombia a principios del siglo XX. Por ello, si bien las FARC-EP se fundan oficialmente en 1964 bajo el nombre inicial de "Bloque Sur", enarbolan en su lucha importantes reclamaciones relacionadas al contexto de desigualdad social, distribución inequitativa respecto a la propiedad de la tierra y adecuada participación política que ya se evidenciaban en Colombia desde principios de siglo.

En medio de la negociación de paz que las partes han desarrollado, se han establecido en el acuerdo las garantías necesarias de no repetición, propias de un proceso transicional. Frente a este elemento, adquiere especial importancia la posibilidad de participación política de las FARC-EP en la vida democrática nacional, ya no como organización armada, sino como grupo político dentro de la legalidad.

Esta circunstancia responsabiliza al Gobierno nacional para adoptar todas las medidas que sean necesarias para asegurar que ningún partido o movimiento político en Colombia, sin importar su denominación o ideología, vuelva a ser victimizado como en el pasado ocurrió con las FARC-EP. En tal virtud, el Estado se compromete a adoptar medidas que materialicen el otorgamiento de derechos y garantías plenas para el ejercicio de la oposición política en general, y en particular para los nuevos movimientos que surjan luego de la firma del acuerdo final de paz. Estas medidas incluyen el acceso a medios de comunicación, la adopción del Estatuto de garantías para el ejercicio de la oposición política, la implementación de un Sistema Integral para el Ejercicio de la política, la promoción de garantías de seguridad para líderes de organizaciones y movimientos sociales y defensores de derechos humanos, entre otras.

La participación política, por ende, se constituye como un punto neurálgico en la transición hacia el post-conflicto, y el acuerdo obtenido entre las partes precisamente reconoce la naturaleza política que engendró el movimiento subversivo décadas atrás, reconoce a las FARC-EP como un interlocutor político, proporciona garantías para su papel como eventual contrincante en el juego democrático y permite que aquellos miembros que aún siendo sancionados por el modelo transicional acordado por las partes, puedan efectivamente participar en política. 
Bibliografía

Acuerdo final para la terminación del conflicto y la construcción de una paz estable y duradera. Disponible desde http://www.altocomisionadoparalapaz.gov.co/procesos-yconversaciones/Documentos\%20compartidos/24-11-2016NuevoAcuerdoFinal.pdf (ultimo acceso 04/07/2017).

Centro Nacional de Memoria Histórica. (2014). Guerrilla y población civil trayectoria de las FARC 1949-2013. Bogotá: Imprenta Nacional de Colombia. Disponible desde http://www.centrodememoriahistorica.gov.co/descargas/informes2013/farc/guerrillapoblacion-civil.pdf (ultimo acceso 04/07/2017).

Gutiérrez, F., Acevedo, T., \& Viatela, J. (2007). Violent liberalism?: State, Conflict and Political Regime in Colombia (1930-2006), an Analytical Narrative on State-Making. Crisis States Working Papers, 2, 1-71.

Duque, J. (2005). La circulación de la clase política en Colombia: El Congreso de la República durante el frente Nacional. Revista Sociedad Y Economía., 8, 29-60.

Mesa, E. (2009). El Frente Nacional y su naturaleza antidemocrática. Revista Facultad De Derecho Y Ciencias Políticas, 39(110), 157-184.

Pizarro, E. (2011). Las Farc (1949-2011): De guerrilla campesina a máquina de guerra. Bogotá: Grupo Editorial Norma.

Trejos, L., \& González, R. (2013). El Partido Comunista Colombiano y la combinación de todas las formas de lucha. Entre la simpatía internacional y las tensiones locales, 19611981. Revista Izquierdas, (17), 64-80.

Trejos, L. (2015). Un actor no estatal en el escenario internacional: El caso de las Fuerzas Armadas Revolucionarias de Colombia, FARC-EP, 1966-2010. Barranquilla: Universidad del Norte. 